\title{
Derivation and validation of a prediction score for acute kidney injury secondary to acute myocardial infarction in Chinese patients
}

Feng-bo Xu, Hong Cheng ${ }^{*}$, Tong Yue, Nan Ye, He-jia Zhang and Yi-pu Chen

\begin{abstract}
Background: Acute kidney injury (AKI) is a major complication of acute myocardial infarction(AMI), which can significantly increase mortality. This study is to analyze the related risk factors and establish a prediction score of acute kidney injury in order to take early measurement for prevention.

Methods: The medical records of 6014 hospitalized patients with AMI in Beijing Anzhen Hospital from January 2010 to December 2016 were retrospectively analyzed. These patients were randomly assigned into two cohorts: one was for the derivation of prediction score $(n=4252)$ and another for validation $(n=1762)$. The criterion for AKI was defined as an increase in serum creatinine of $\geq 0.3 \mathrm{mg} / \mathrm{dL}$ or $\geq 50 \%$ from baseline within $48 \mathrm{~h}$. On the basis of odds ratio obtained from multivariate logistic regression analysis, a prediction score of acute kidney injury after AMl was built up.

Results: In this prediction score, risk score 1 point included hypertension history, heart rate $>100 \mathrm{bpm}$ on admission, peak serum troponin $I \geq 100 \mu \mathrm{g} / \mathrm{L}$, and time from admission to coronary reperfusion $>120 \mathrm{~min}$; risks score 2 points included Killip classification $\geq$ class 3 on admission; and maximum dosage of intravenous furosemide $\geq 60 \mathrm{mg} / \mathrm{d}$; risks score 3 points only included shock during hospitalization. In addition, when baseline estimated glomerular filtration rate (eGFR) was less than $90 \mathrm{ml} / \mathrm{min} \cdot 1.73 \mathrm{~m}^{2}$, every $10 \mathrm{ml} / \mathrm{min} \cdot 1.73 \mathrm{~m}^{2}$ reduction of eGFR increased risk score 1 point. Youden index showed that the best cut-off value for prediction of AKI was 3 points with a sensitivity of $71.1 \%$ and specificity $74.2 \%$. The datasets of derivation and validation both displayed adequate discrimination (an area under the ROC curve, 0.79 and 0.81 , respectively) and satisfactory calibration (Hosmer-Lemeshow statistic test, $P=0.63$ and $P=0.60$, respectively).
\end{abstract}

Conclusions: In conclusion, a prediction score for AKI secondary to AMI in Chinese patients was established, which may help to prevent AKI early.

Keywords: Acute kidney injury, Acute myocardial infarction, Prediction score

\footnotetext{
* Correspondence: drhongcheng@163.com

Department of Nephrology, Beijing Anzhen Hospital, Capital Medical

University, Beijing, People's Republic of China
}

(c) The Author(s). 2019 Open Access This article is distributed under the terms of the Creative Commons Attribution 4.0 International License (http://creativecommons.org/licenses/by/4.0/), which permits unrestricted use, distribution, and reproduction in any medium, provided you give appropriate credit to the original author(s) and the source, provide a link to the Creative Commons license, and indicate if changes were made. The Creative Commons Public Domain Dedication waiver (http://creativecommons.org/publicdomain/zero/1.0/) applies to the data made available in this article, unless otherwise stated. 


\section{Background}

Acute kidney injury (AKI) has been reported to be a frequent complication of acute myocardial infarction (AMI) which is known to be associated with adverse outcomes [1]. The incidence of AKI in patients with AMI was 8.7 to $36.6 \%$ in the past 10 years [1-8]. AKI is associated with high mortality and also predicts the future risk for end-stage renal disease [8-11].

The mechanisms causing AKI secondary to AMI are multifactorial [12]. The key mechanisms in AKI pathogenesis including systemic and renal hemodynamic changes secondary to impaired cardiac output and increased venous congestion. Moreover, an imbalance of endogenous vasodilating and vasoconstrictive factors appears to be involved. A burst of immunological and inflammatory activation were the potential causes of further renal injury [12]. Several studies proposed certain risk factors for AKI secondary to AMI, including advanced age $[6,13,14]$, admission hyperglycemia [15, 16], impaired renal function at presentation $[5,6,13]$, and prolonged duration to coronary reperfusion [17]. There were some prediction scores of AKI after the percutaneous coronary intervention (PCI) for AMI [18-21]. However, only few studies have developed prediction scores including all the AMI patients which undergoing PCI or not [22, 23]. In 2012, Queiroz et al. created a prediction score for AKI secondary to AMI [22]. Nonetheless, the sample size was small (406 patients) and employed only for the clinical manifestation of ST-segment elevation myocardial infarction (STEMI) in the emergency department, thereby exhibiting some limitations. Recently, Abusaoda et al. developed a novel score to predict the risk of AKI secondary to AMI [23]. The study included a total of 1107 patients and the area under the receiver operating characteristic (ROC) curve (AUC) was 0.76 . The above two prediction scores were primarily screened for those with AKI risk factors involve just at admission. The current study included patients with STEMI and non-STEMI, which undergoing PCI or not. This study analyzed the risk factors of AKI on admission as well as some potential risk factors of AKI also involve in the duration of hospital stay, and the prediction score was established with all these presentations. Therefore our prediction score showed adequate discrimination and good calibration, which could be used to screen the high-risk patients for AKI secondary to AMI more comprehensively and to help clinicians taking better preventive interventions.

\section{Methods}

\section{Study design}

We consecutively enrolled patients with AMI from Beijing Anzhen Hospital, one of the biggest cardiology center in China, from January 1, 2010 to December 31,
2016. All patients presented a primary diagnosis of AMI (STEMI or non-STEMI), and admitted to hospital within $24 \mathrm{~h}$ of onset of an ischemic event. The diagnosis of AMI was established by a typical history of chest pain, diagnostic electrocardiographic changes, and a successive elevation of serum cardiac biomarkers [24]. Exclusion criteria were (1) length of hospital stay< 2 days, (2) lacking sufficient inspection of serum creatinine ( $\mathrm{SCr}$ ), (3) pre-existing end stage renal disease requiring dialysis. The final analytic data from 6014 patients were included in our study. These patients were randomly assigned into two groups. The first group, comprising $70 \%$ of the patients $(n=4252)$, was used to derive the prediction score and the other group, consisting of the remaining $30 \%$ ( $n=1762)$ patients, was used to validate the prediction score.

The definition of AKI was based on the change of measurements with $\mathrm{SCr}$ on admission using the AKI Network (AKIN) criteria. It was defined as an absolute increase in SCr levels of $\geq 0.3 \mathrm{mg} / \mathrm{dL}(26.4 \mu \mathrm{mol} / \mathrm{L})$ or as a percent increase in $\mathrm{SCr}$ of $\geq 50 \%$ from baseline within $48 \mathrm{~h}$. Moreover, AKI was classified into 3 stages based on an increase of $50-100 \%$ in baseline SCr (stage 1), $100-200 \%$ (stage 2), or $>300 \%$ or an increment of 0.5 $\mathrm{mg} / \mathrm{dL}(44.2 \mu \mathrm{mol} / \mathrm{L})$ if the baseline $\mathrm{SCr}$ was $>4.0 \mathrm{mg} / \mathrm{dL}$ (353.6 $\mu \mathrm{mol} / \mathrm{L})$ (stage 3) [25]. Due to the retrospective nature of the study, urine output in most patients was not monitored, and related data could not be obtained, and hence, this study did not consider the urine output standard.

Data on the following variables that might influence AKI development were collected: demographic data, previous history, clinical data, laboratory data, echocardiography data, and in-hospital treatment. Baseline $\mathrm{SCr}$ was defined as the value measured on admission. The baseline estimated glomerular filtration rate (eGFR) was calculated using the Modification of Diet in Renal Diseases (MDRD) equation for Chinese patients: eGFR $\left(\mathrm{mL} / \mathrm{min} \cdot 1.73 \mathrm{~m}^{2}\right)=175 \times \mathrm{SCr}(\mathrm{mg} / \mathrm{dL})^{-1.234} \mathrm{x}$ Age $^{-0.179}$ ( $\times 0.79$ for women) [26]. The dosage of loop diuretics was expressed as furosemide equivalents ( $1 \mathrm{mg}$ bumetanide $\approx 20 \mathrm{mg}$ torsemide $\approx 40 \mathrm{mg}$ furosemide).

A standardized data abstraction form was designed for data collection. The hospital records were abstracted by the trained medical record technicians. The strategies to decrease abstraction errors and variability included training sessions and detailed data definition.

\section{Statistical analysis}

The continuous variables with normal distribution were presented as mean \pm standard deviation, and $t$-test was used for univariate comparison. On the other hand, those with non-normal distribution were represented as median and interquartile range, and Wilcoxon-Mann- 
Whitney test was used for univariate comparison. The categorical variables were reported as percentages, and the chi-square test was used for univariate comparison. List wise deletion was used for missing data. The variables with $P \leq 0.05$ in univariate comparison were included in the multivariate logistic regression analysis. Based on the odds ratio (OR) in the final multivariate logistic regression model, the risk factors for AKI were assigned weighted integers, and the prediction score was created. Discrimination of the prediction score was assessed using the ROC curve. Calibration was assessed using the Hosmer-Lemeshow goodness-of-fit test and satisfied when $P$ value was $>0.05$. The comparison of AUC between Abusaoda's prediction score and our prediction score was done using the test proposed by DeLong et al. [27].

SPSS software version 17.0 (IBM Inc., Armonk, NY, USA) was used to analyze the data. For all analyses, $P<0.05$ was considered as statistically significant.

\section{Results}

Incidence of AKI and in-hospital outcome

A total data from 6014 AMI patients, with mean age $58.00 \pm 11.74$ years, were recruited; and $80.5 \%$ of the patients consisted of males. AKI occurred in 675 patients (11.2\%) including 9.5\% stage $1,1.1 \%$ stage 2 , and $0.6 \%$ stage 3 . The mortality rate was $10.1 \%$ in patients who developed AKI and $1.6 \%$ in those without AKI $(P<0.05)$. The mortality rate of the former was 6.31-fold higher than that of the latter. Moreover, the length of hospital stay in patients with AKI significantly prolonged with a median of 9 days (interquartile range, $6-14$ days) as compared to 7 days (interquartile range, $5-9$ days) in the patients without AKI $(P<0.05)$.

\section{Baseline characteristics and univariate analysis}

The demographic data, previous history, clinical data, laboratory data, echocardiography data and in-hospital treatment of the patients in derivation cohort are shown in Table 1. The univariate comparison of potential predictor variables between AKI and non-AKI patients in the derivation cohort is also shown in Table 1. A total of 42 variables with $P<0.05$ in Table 1 were involved in the multivariate logistic regression model, but the data regarding $\mathrm{N}$-terminal pro-B-type natriuretic peptide, glycosylated hemoglobin and echocardiographic parameters were excluded in the logistic regression because that these data were absent in more than $10 \%$ of study subjects.

\section{Multivariable analysis and derivation of prediction score}

The results of multivariable logistic regression analysis of backward stepwise variable selection in 4025 patients (representing 94.7\% of the derivation cohort) are shown in Table 2.
The independent risk factors and prediction score for AKI were as follows: risk score 1 point included hypertension history [OR 1.45, 95\% confidence interval (CI): 1.15-1.84], heart rate $>100 \mathrm{bpm}$ on admission (OR 1.75, 95\% CI: 1.20-2.55), peak troponin $\mathrm{I} \geq 100 \mu \mathrm{g} / \mathrm{L}$ (OR 1.74, 95\% CI: 1.34-2.26), and time from admission to coronary reperfusion $>120 \mathrm{~min}$ (OR 1.36, 95\% CI: 1.08-1.72); risks score 2 points included killip classification [28] $\geq$ class 3 during admission (OR 1.99, 95\% CI: 1.45-2.75) and maximum dosage of intravenous furosemide $\geq 60 \mathrm{mg} / \mathrm{d}$ (OR 2.94, 95\% CI 1.74-4.99); risks score 3 points only included shock during hospitalization (OR 3.81, 95\% CI 2.75-5.28). In addition, when baseline eGFR was less than $90 \mathrm{ml} / \mathrm{min} \cdot 1.73 \mathrm{~m}^{2}$, every $10 \mathrm{ml} / \mathrm{min} \cdot 1.73 \mathrm{~m}^{2}$ reduction of eGFR (OR 1.52 , 95\%CI 1.43-1.62) increased risk score 1 point (Tables 2 and 3).

The prediction score included 8 variables that ranged from 0 to 18 points. Furthermore, patients were categorized into 4 risk groups based on the scores: low risk (0-3 points, $4.8 \%$ incidence of $\mathrm{AKI}$ ), intermediate risk (4-7 points, $13.4 \%$ incidence of AKI); high risk (8-11 points, $46.7 \%$ incidence of AKI), and very high risk ( $\geq 12$ points, 81.2\% incidence of AKI)(Table 4). To determine the optimal threshold value for predicting AKI, Youden index was used, and the best cut-off in the present model was 3 points (with a sensitivity of $71.1 \%$ and specificity $74.2 \%$ ). The incidence of AKI was significantly higher in patients with scores $>3$ points than those with scores $\leq 3$ points (23.0\% vs. $4.8 \%, P<0.001)$.

The prediction score displayed adequate discrimination between patients with or without AKI (AUC: 0.79, 95\% CI 0.76-0.81) (Fig. 1a). It was well calibrated across deciles of observed and expected risks of AKI (HosmerLemeshow chi-square value was 6.19, $P=0.63$ ) (Fig. 2a).

\section{Validation of prediction score}

An adequate discriminative power was also demonstrated in the validation cohort with an AUC of 0.81 (95\% CI: 0.77-0.85) (Fig. 1b). The result of Hosmer-Lemeshow test in the validation cohort was not statistically significant with Chi-square value 3.64 , $P=0.60$ (Fig. 2b).

\section{External validation of Abusaoda's prediction score}

The prediction score established by Abusaoda based on the definition of AKIN, and it consisted of seven prediction factors including cardiac arrest, decompensated heart failure at admission, diabetes mellitus, hypertension, anemia, impaired renal function at admission, and tachycardia at admission. Because the population of this study was similar to our study and the seven prediction factors in Abusaoda's prediction scores were all involved in our study, the external validation of this prediction score was performed by us in our total 6014 patients, and the AUC was 0.73 (95\% CI: 0.71-0.75). While, using 
Table 1 Baseline characteristics of the patients and univariate comparisons in derivation cohort

\begin{tabular}{|c|c|c|c|c|}
\hline Variable & $\begin{array}{l}\text { All patients } \\
(n=4252)\end{array}$ & $\begin{array}{l}\text { Non-AKI } \\
(n=3767)\end{array}$ & $\begin{array}{l}\text { AKI } \\
(n=485)\end{array}$ & $p$ value \\
\hline \multicolumn{5}{|l|}{ Demographic data } \\
\hline Male, $n(\%)$ & $3414(80.3)$ & $3042(80.8)$ & $372(76.7)$ & 0.035 \\
\hline Age, (years) & $58.2 \pm 11.6$ & $57.8 \pm 11.5$ & $61.4 \pm 12.5$ & $<0.001$ \\
\hline \multicolumn{5}{|l|}{ Medical history } \\
\hline Hypertension, n (\%) & $2422(57)$ & $2094(55.6)$ & $328(67.6)$ & $<0.001$ \\
\hline Diabetes mellitus, n (\%) & $1236(29.1)$ & $1062(28.2)$ & $174(35.9)$ & $<0.001$ \\
\hline CVD, $n(\%)$ & $1092(25.7)$ & $948(25.2)$ & $144(29.7)$ & 0.030 \\
\hline Atrial fibrillation, $n(\%)$ & 109 (2.6) & $91(2.4)$ & $18(3.7)$ & 0.089 \\
\hline CKD, n (\%) & $144(3.4)$ & $71(1.9)$ & $73(15.1)$ & $<0.001$ \\
\hline Hyperlipemia, n (\%) & $1287(30.3)$ & $1166(31)$ & $121(24.9)$ & 0.007 \\
\hline Cerebral infarction, $n$ (\%) & $413(9.7)$ & $344(9.1)$ & $69(14.2)$ & $<0.001$ \\
\hline Previous PCl, n (\%) & $508(11.9)$ & $436(11.6)$ & $72(14.8)$ & 0.037 \\
\hline \multicolumn{5}{|l|}{ Clinical data } \\
\hline Extensive anterior $\mathrm{Ml}, n(\%)$ & $700(16.5)$ & $584(15.5)$ & $116(24)$ & $<0.001$ \\
\hline STEMI, n (\%) & $3251(76.5)$ & $2856(75.8)$ & $395(81.4)$ & 0.006 \\
\hline Killip class $\geq 3$ & $426(10.0)$ & $255(6.8)$ & $171(35.3)$ & $<0.001$ \\
\hline Time from AMI attack on admission, (h) & $6(3-14)$ & $6(3-14)$ & $6.5(3-14)$ & 0.656 \\
\hline Time from AMI attack to reperfusion, (h) & $6(4-10)$ & $6(4-9.5)$ & $6(4-11)$ & 0.097 \\
\hline Time from admission to reperfusion > 120 min, $n(\%)$ & $2196(51.6)$ & $1916(50.9)$ & $280(57.7)$ & 0.004 \\
\hline Coronary angiography, $n$ (\%) & $3884(91.3)$ & $3497(92.9)$ & $387(79.8)$ & $<0.001$ \\
\hline Primary $\mathrm{PCl}, n(\%)$ & $2374(55.8)$ & $2110(56)$ & $264(54.5)$ & 0.532 \\
\hline Left main artery, n (\%) & $254(6.0)$ & $210(6.0)$ & $44(11.4)$ & $<0.001$ \\
\hline Two or more culprit lesions, $n(\%)$ & $2266(53.3)$ & $2029(57.8)$ & $237(61.4)$ & 0.171 \\
\hline Ventricular fibrillation, n (\%) & $137(3.2)$ & $91(2.4)$ & $46(9.5)$ & $<0.001$ \\
\hline 3 degree atrioventricular block, $n(\%)$ & $57(1.3)$ & $34(0.9)$ & $23(4.7)$ & $<0.001$ \\
\hline Cardiac arrest, $n$ (\%) & $138(3.2)$ & $91(2.4)$ & $47(9.7)$ & $<0.001$ \\
\hline Shock during hospitalization, $n(\%)$ & $366(8.6)$ & $202(5.4)$ & $164(33.8)$ & $<0.001$ \\
\hline Heart rate $>100$ bpm on admission & $243(5.7)$ & $171(4.5)$ & $72(14.8)$ & $<0.001$ \\
\hline Systolic BP on admission, (mmHg) & $120.5 \pm 19.4$ & $120.9 \pm 18.9$ & $117.9 \pm 22.7$ & 0.006 \\
\hline Diastolic BP on admission, (mmHg) & $74.0 \pm 11.9$ & $74.2 \pm 11.7$ & $73.0 \pm 13.3$ & 0.057 \\
\hline \multicolumn{5}{|l|}{ echocardiography data } \\
\hline Initial LVEF on admission, (\%) & $54.6 \pm 9.8$ & $55.1 \pm 9.5$ & $50.7 \pm 11.1$ & $<0.001$ \\
\hline Initial LVDd on admission, (mm) & $49.3 \pm 5.4$ & $49.2 \pm 5.3$ & $49.9 \pm 6.2$ & 0.051 \\
\hline Initial RVDd on admission, (mm) & $21.0 \pm 5.5$ & $21.0 \pm 5.6$ & $21.0 \pm 3.8$ & 0.537 \\
\hline E/A > 1 on admission, $n$ (\%) & $1263(38.4)$ & $1123(38.7)$ & $140(36.6)$ & 0.442 \\
\hline \multicolumn{5}{|l|}{ Laboratory data } \\
\hline Serum creatinine on admission, (umol/L) & $74.9(64.4-88.1)$ & $73.8(64.0-85.7)$ & $89.0(70.1-115.8)$ & $<0.001$ \\
\hline eGFR on admission, $\left[\mathrm{ml} /\left(\min \cdot 1.73 \mathrm{~m}^{2}\right)\right]$ & $100.6(82.6-121.6)$ & $102.3(85.4-122.7)$ & $80.0(56.0-105.6)$ & $<0.001$ \\
\hline hCRP on admission, (mg/L) & $7.8(3.0-19.4)$ & $7.3(2.8-18.0)$ & $11.5(4.5-30.5)$ & $<0.001$ \\
\hline FBG on admission, (mmol/L) & $6.0(5.4-7.4)$ & $6.0(5.3-7.3)$ & $6.5(5.6-8.4)$ & $<0.001$ \\
\hline HBA1C, (\%) & $6.5 \pm 1.5$ & $6.5 \pm 1.5$ & $6.6 \pm 1.4$ & 0.035 \\
\hline Serum sodium on admission, (mmol/L) & $139.1 \pm 3.6$ & $139.2 \pm 3.5$ & $138.3 \pm 4.0$ & $<0.001$ \\
\hline Serum calcium on admission, (mmol/L) & $2.2 \pm 0.1$ & $2.2 \pm 0.1$ & $2.2 \pm 0.2$ & $<0.001$ \\
\hline
\end{tabular}


Table 1 Baseline characteristics of the patients and univariate comparisons in derivation cohort (Continued)

\begin{tabular}{|c|c|c|c|c|}
\hline Variable & $\begin{array}{l}\text { All patients } \\
(n=4252)\end{array}$ & $\begin{array}{l}\text { Non-AKI } \\
(n=3767)\end{array}$ & $\begin{array}{l}\text { AKI } \\
(n=485)\end{array}$ & $p$ value \\
\hline Albumin on admission, (g/L) & $39.2 \pm 4.1$ & $39.3 \pm 3.9$ & $37.9 \pm 5.0$ & $<0.001$ \\
\hline Uric acid on admission, (umol/L) & 328.9 (270.9-394.9) & $326.8(268.7-390.4)$ & $357.0(283.8-432.2)$ & $<0.001$ \\
\hline Totalcholesterol, (mmol/L) & $4.6 \pm 1.1$ & $4.6 \pm 1.1$ & $4.5 \pm 1.1$ & 0.175 \\
\hline Triglyceride, (mmol/L) & $1.5(1.1-2.2)$ & $1.5(1.1-2.2)$ & $1.4(1.0-2.0)$ & 0.158 \\
\hline Low density lipoprotein, (mmol/L) & $2.9 \pm 0.9$ & $2.9 \pm 0.9$ & $2.8 \pm 0.9$ & 0.008 \\
\hline High density lipoprotein, (mmol/L) & $1.0 \pm 0.3$ & $1.0 \pm 0.2$ & $1.1 \pm 0.3$ & 0.102 \\
\hline Leukocyte on admission, $\left(\times 10^{9} / \mathrm{L}\right)$ & $10.2 \pm 3.6$ & $10.0 \pm 3.5$ & $11.2 \pm 4.2$ & $<0.001$ \\
\hline Hemoglobin on admission, (g/L) & $143.4 \pm 17.2$ & $144.3 \pm 16.5$ & $137.3 \pm 20.7$ & $<0.001$ \\
\hline Hematocrit on admission, (\%) & $41.5 \pm 4.5$ & $41.7 \pm 4.3$ & $40.1 \pm 5.4$ & $<0.001$ \\
\hline Peak serum TNI $\geq 100$ ng/ml, n(\%) & $802(18.7)$ & $644(17.1)$ & $158(32.6)$ & $<0.001$ \\
\hline Peak serum MB, (ug/L) & $112.3(34.0-265.3)$ & $107.5(32.2-257.2)$ & $173.4(53.1-299.0)$ & $<0.001$ \\
\hline NT-ProBNP on admission, (pg/mL) & $115(41-327)$ & $104(39-259)$ & $378(89-1035)$ & $<0.001$ \\
\hline \multicolumn{5}{|l|}{ Treatment } \\
\hline Furosemide dosage $\geq 60 \mathrm{mg} / \mathrm{d}, n(\%)$ & $102(2.4)$ & $47(1.2)$ & $55(11.3)$ & $<0.001$ \\
\hline Intravenous nitrates, n (\%) & 1689 (39.7) & $1442(38.3)$ & $249(50.9)$ & $<0.001$ \\
\hline$\beta$-blocker, $n$ (\%) & $3253(76.5)$ & $2905(77.1)$ & $348(71.9)$ & 0.011 \\
\hline ACEI/ARB, n (\%) & $2543(59.8)$ & $2269(60.2)$ & $274(56.5)$ & 0.114 \\
\hline Intravenous thrombolysis, $n$ (\%) & $212(5.0)$ & $171(4.5)$ & $41(8.5)$ & $<0.001$ \\
\hline Use of IABP, $n(\%)$ & $174(4.1)$ & $107(2.8)$ & $67(13.8)$ & $<0.001$ \\
\hline Pulmonary mechanical Ventilation, $n$ (\%) & $192(4.5)$ & $127(3.4)$ & 66 (13.6) & $<0.001$ \\
\hline Temporary pacemaker, n (\%) & $47(1.1)$ & $31(10.8)$ & $16(3.3)$ & $<0.001$ \\
\hline Contrast volume, (mL) & $185.5 \pm 102.0$ & $189.7 \pm 101.0$ & $153.2 \pm 104.0$ & $<0.001$ \\
\hline
\end{tabular}

CVD cardiovascular disease, $C K D$ chronic kidney disease, $P C I$ percutaneous coronary intervention, $A M I$ acute myocardial infarction, $B P$ blood pressure, $L V E F$ left ventricular ejection fraction, $L V D d$ left ventricular end-diastolic dimension, RVDd right ventricular end-diastolic dimension, eGFR estimation of glomerular filtration rate, $h S C R P$ high sensitivity C-reactive protein, FBG fast blood glucose, HBA1C glycosylated hemoglobin, $T N I$ troponin I, CK-MB creatine kinase isoenzyme, NT-

ProBNP N-terminal pro-B-type natriuretic peptide, $A C E I$ angiotensin converting enzyme inhibitor, $A R B$ angiotensin receptor blocker, IABP intra-aortic balloon pump

our prediction score in the same group of patients, the AUC was 0.78 (95\% CI: 0.76-0.80, $P<0.05$ ).

\section{Discussion}

AKI is one of the major complication in AMI patients. The incidence of AKI was reported to be $8.7-36.6 \%$ in AMI patients due to the differences in the subjects and the diagnostic criteria [1-8]. In our study, the incidence of AKI in patients with AMI was $11.2 \%$, which was within the scope of the previous literature reports [1-8]. The hospital mortality induced by AKI was also higher: 9.2-39.6\% [1, 2, 29, 30]. In the present study, the hospital mortality increased significantly in patients with AKI compared with those without AKI (10\% vs. $1.6 \%, P<0.05)$, and the length of hospital stay obviously prolonged. In ACTION registry, the in-hospital

Table 2 Multivariate logistic regression in derivation cohort

\begin{tabular}{llll}
\hline Variable & $\beta$ & Odds ratio $(95 \% \mathrm{Cl})$ & $p$ value \\
\hline History of hypertension & 0.372 & $1.45(1.15-1.84)$ & 0.002 \\
Killip classification $\geq$ class 3 & 0.694 & $1.99(1.45-2.75)$ & $3.81(2.75-5.28)$ \\
Shock during hospitalization & 1.344 & $1.52(1.43-1.62)$ & $<.001$ \\
Every $10 \mathrm{ml} /\left(\mathrm{min} .1 .73 \mathrm{~m}^{2}\right)$ decline of eGFR under $90 \mathrm{ml} /\left(\mathrm{min} .1 .73 \mathrm{~m}^{2}\right)$ & 0.422 & $1.75(1.20-2.55)$ & $1.74(1.34-2.26)$ \\
$\mathrm{HR}>100 \mathrm{bpm}$ at admission & 0.564 & 0.001 \\
Peak serum troponin $\geq 100 \mathrm{ng} / \mathrm{mL}$ & 0.552 & $0.36(1.08-1.72)$ & 0.004 \\
Time to reperfusion $>120 \mathrm{~min}$ & 0.312 & 1.082 & $2.94(1.74-4.99)$
\end{tabular}


Table 3 Prediction score forAKI

\begin{tabular}{ll}
\hline Risk factor & risk score \\
\hline History of hypertension & 1 \\
Killip classification $\geq$ class 3 & 2 \\
Shock during hospitalization & 3 \\
HR $>100$ bpm on admission & 1 \\
eGFR [ml/(min $\left.\left.1.73 \mathrm{~m}^{2}\right)\right]$ on admission & \\
$80-89.9$ & 1 \\
$70-79.9$ & 2 \\
$60-69.9$ & 3 \\
$50-59.9$ & 4 \\
$40-49.9$ & 5 \\
$30-39.9$ & 6 \\
$\leq 29.9$ & 7 \\
Peak serum troponin $\geq 100 \mathrm{ng} / \mathrm{mL}$ & 1 \\
Time to reperfusion $>120 \mathrm{~min}$ & 1 \\
Intravenous furosemide $\geq 60 \mathrm{mg} / \mathrm{d}$ & 2
\end{tabular}

eGFR estimation of glomerular filtration rate, $H R$ heart rate

mortality of patients with AKI was $15 \%$, which was 7.5-fold higher than those without AKI (2\%) [1]. Moreover, the occurrence of AKI also affected the long-term prognosis in AMI patients and reduced the long-term survival rate $[11,31]$. Therefore, currently, reducing the incidence and mortality of AKI in patients with AMI should be solved urgently. Establishment of the prediction score would provide the foundation for preventing AKI.

A majority of the published studies showed that basal renal dysfunction was the major risk factor for AKI [11, $22,23,32]$. Our study confirmed this also. The risk of AKI increased 1.52-fold when the baseline eGFR decreased by per $10 \mathrm{~mL} / \mathrm{min} \cdot 1.73 \mathrm{~m}^{2}$. Patients with baseline renal dysfunction may be with poor renal reserve function as well as low compensatory ability [33]. After the occurrence of AMI, these patients will be suffered from heart and kidney hypoperfusion and strong stress response, thereby their renal function will be damaged heavily. Previous studies have shown that elderly patients who always have a poor renal reserve capacity was a risk factor for AKI [18-21, 23]. However, the same results

Table 4 Incidence of acute kidney injury according to prediction score

\begin{tabular}{lllll}
\hline Score risk category & score & total patients $(\mathrm{n})$ & AKI $(\mathrm{n}, \%)$ & Death $(\mathrm{n}, \%)$ \\
\hline Low & $0-3$ & 2711 & $130(4.8)$ & $9(0.3)$ \\
Intermediate & $4-7$ & 1184 & $159(13.4)$ & $17(2.0)$ \\
High & $8-11$ & 272 & $127(46.7)$ & $25(12.1)$ \\
Very high & $\geq 12$ & 85 & $69(81.2)$ & $18(31.0)$ \\
\hline
\end{tabular}

The score ranged from 0 to 18 points were not obtained in this study, which may be related to the age factor being revised when the modified MDRD formala was used to eGFR. In our study, we also found that hypertension was an independent predictor of AKI in patients with AMI, which was consistent with the results of the previous study $[1,22]$. Patients with continuous hypertension may result in renal arteriolosclerosis, which leading to chronic renal injury and basal renal dysfunction [34, 35].

In our study, the risk of AKI in patients with killip classification $\geq$ class 3 during admission was 1.99 -fold higher than those with killip classification < class 3. In a retrospective analysis of the data from 2798 patients with AMI, Kuji et al. found that the incidence of AKI in killip 1, killip 2-3, and killip 4 patients were 6.7, 15.3, and $31.3 \%$, respectively [36]. Also, with the worsening of cardiac function, the incidence of AKI increased gradually. Another retrospective study based on the data of 5244 patients with AMI showed that killip 3 or 4 was an independent risk factor for AKI [13], which was consistent with our conclusion. In addition, the risk of AKI in patients with shock was 3.81-fold higher than those without shock, which is similar to other study previously [1]. Finally, we also found that the risk of AKI in patients with troponin $\mathrm{I} \geq 100 \mu \mathrm{g} / \mathrm{L}$ was 1.74 -fold higher than those patients with troponin $\mathrm{I}<100 \mu \mathrm{g} / \mathrm{L}$. This might be because that troponin $\mathrm{I} \geq 100 \mu \mathrm{g} / \mathrm{L}$ were closely related with the occurrence of cardiogenic shock and heart failure [37]. All these three factors can reduce cardiac output, then lead to the decline of renal perfusion as well as renal ischemia, result in AKI ultimately. Recent studies found that patients of heart failure with lower left ventricular ejection fraction, could result in insufficient renal perfusion because of reduced cardiac output. Moreover, the increase of peripheral venous pressure and intraabdominal pressure caused by right cardiac insufficiency can reduce the effective blood flow of the kidneys and activate the inflammatory factors, then caused AKI similarly [38-42].

In the previous two prediction scores created by Queiroz and Abusaada, tachycardia was an independent risk factor for AKI and was included in the prediction score [22, 23]. The similar conclusion was drawn from our study: we found the risk of AKI increased by 1.75 times when heart rate $>100 \mathrm{bpm}$ at admission. This might be attributed to that these patients with tachycardia always had a poor heart function which might result in acute reduction of cardiac output and poorer renal perfusion [43].

The time from admission to coronary reperfusion is one powerful prognostic marker of AKI in patients with STEMI, and also which is a key point to improving the survival after STEMI through shorting the total ischemic duration [44, 45]. Other studies have shown that the 

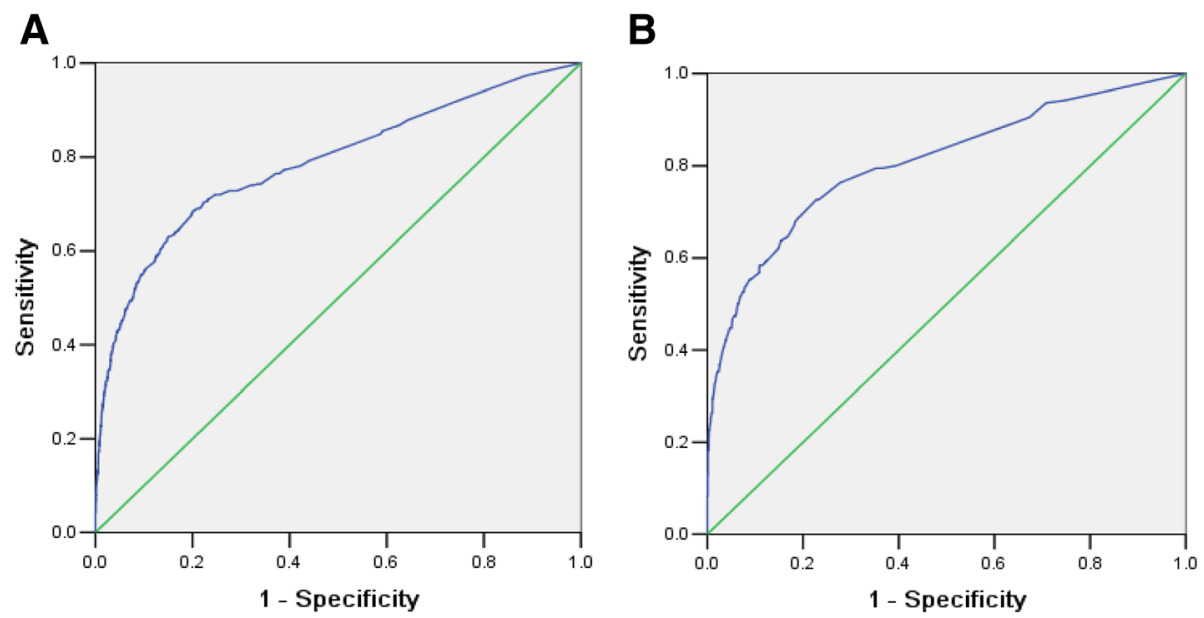

Fig. 1 Area under the ROC curve for the derivation and validation sets. a Derivation sets, area under the ROC curve $0.79(0.76-0.81)$. b Validation sets, area under the ROC curve $0.81(0.77-0.85)$

time to coronary reperfusion is an independent risk factor for the development of AKI in patients with STEMI [16]. Shacham et al. retrospectively analyzed the data from 417 patients of STEMI. The incidence of AKI according to the time to reperfusion was $6.6 \%$ with $<120$ min, $9.7 \%$ with $120-300 \mathrm{~min}$, and $13.3 \%$ with $>300 \mathrm{~min}$. After multivariable regression correction, time to coronary reperfusion still as an independent predictor of AKI [16]. Our study showed a similar conclusion that the time more than $120 \mathrm{~min}$ from admission to coronary reperfusion was an independent risk factor for AKI in patients with AMI. The sudden myocardial insult of AMI often results in an acute reduction of cardiac output and renal perfusion. Early short-time of hemodynamic deterioration only cause a reversible loss of renal function without structural damage of kidney. However, prolonged renal hypoperfusion would lead to acute tubular necrosis ultimately [46]. Therefore, timely recovery of coronary artery perfusion can solve hemodynamic instability, improve left ventricular ejection fraction and solve arrhythmia as well other problems, so as to resume renal perfusion and reduce the incidence of AKI finally [16].

In the present study, we have confirmed that larger dosage of intravenous loop diuretics were the cause of AKI. The risk of AKI in patients with intravenous furosemide dosage $\geq 60 \mathrm{mg} / \mathrm{d}$ was 2.9 -fold higher than those patients with $<60 \mathrm{mg} / \mathrm{d}$. We analyzed the data of 1010 patients with acute heart failure and acute exacerbation of chronic heart failure, and found that the risk of AKI in patients with intravenous furosemide dosage $\geq 80 \mathrm{mg} /$ $\mathrm{d}$ and $\geq 120 \mathrm{mg} / \mathrm{d}$ was nearly 1.96 - and 5.06-fold higher than those with $<80 \mathrm{mg} / \mathrm{d}$ [47]. Although Use of loop diuretics can reduce venous congestion and increase renal blood flow, larger dosage might also reduce circulating blood volume, decrease the renal blood flow, activate the sympathetic and renin-angiotensin system, and increase the peripheral vascular resistance, thereby lead to a decreased renal function [48]. Therefore, the use of diuretics is a double-edged sword, and inappropriate use of larger dosage can lead to renal damage.

Our study did not found the significant relation between contrast volume and AKI, which was consistent with the results of another study [18]. We found the incidence of contrast-induced nephropathy (CIN) in our hospital was only $4.5 \%(177 / 3945)$ [21]. Therefore, we speculate that CIN is no longer a major risk factor for AKI in patients with AMI due to the widely use of isotonic contrast agent and the gradually enhancement of preoperative hydration awareness of cardiologists. So the patients who undergone multiple PCI (i.e., multiple use of contrast agents) were not be excluded in the present study.

Some studies have proposed prediction scores for AKI in the patients with AMI, but most of them were to assess the risk of CIN after PCI or coronary angiography [18-21]. AMI itself also causes deleterious haemodynamic, immunologic and neuroendocrine effects on kidney function except the effects of contrast medium. Moreover, outcome of some AMI patients was not treated with PCI or coronary angiography. Therefore, it is important to create prediction scores for AKI including all the AMI patients which undergoing PCI or not. Presently, two studies have developed prediction scores for AKI in this part of the patients with AMI $[22,23]$. Compared with these two prediction scores, our study has displayed some characteristics as following: Firstly, the prediction score of Queiroz are mainly applicable to identify the risk of AKI in the emergency patients with STEMI [22]. The prediction score from Abusaada can 
A

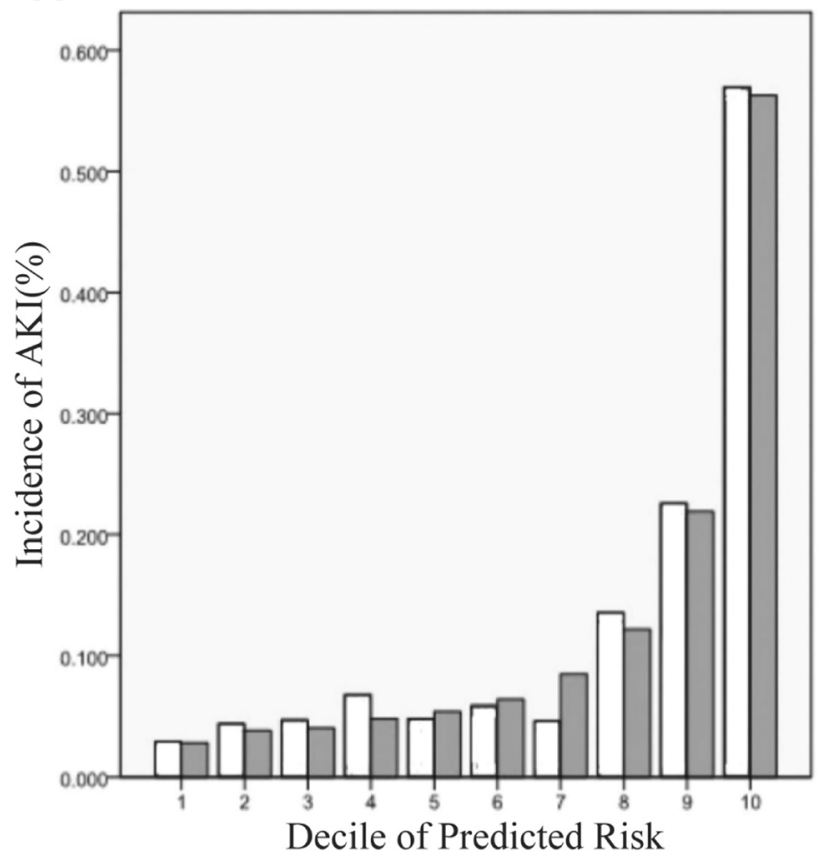

B

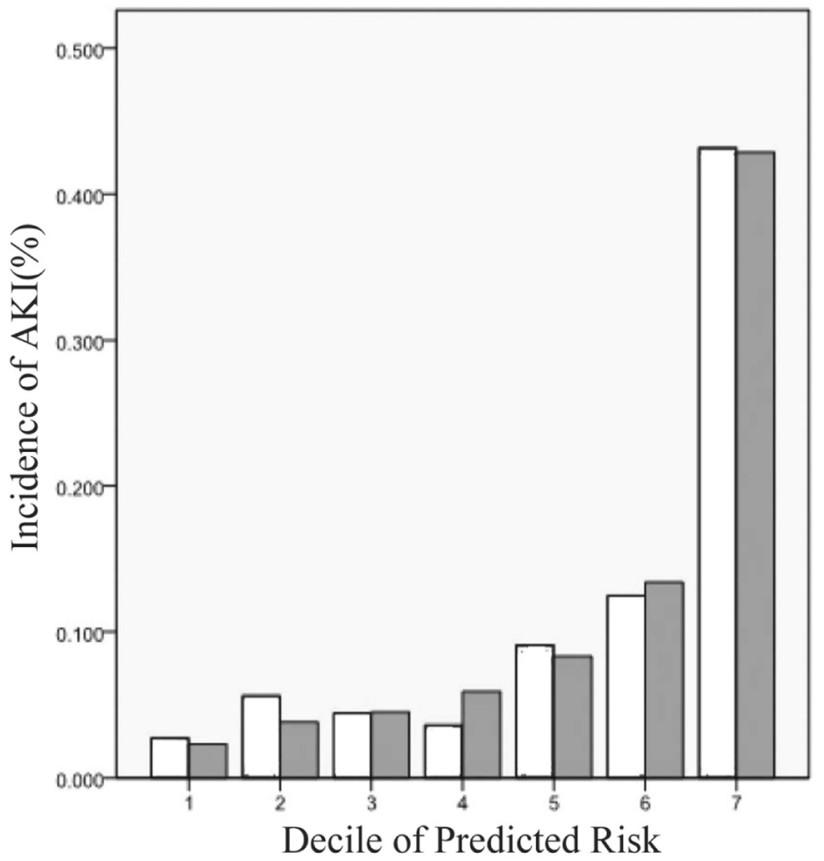

口observed

$\square$ expected

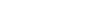


simultaneously assessed the risk of AKI not only during admission but also within hospitalization. Therefore, we think that our prediction score is more valuable to predict the occurrence of AKI. And it also suggests that if there are more risk factors for AKI when patients admitted to hospital, we need to pay more attention to avoiding the side effect of treatment and drugs on the kidney after admission. Secondly, our prediction score have been involved in the time from admission to coronary reperfusion and larger dosage of intravenous loop diuretics, and all of these two were modifiable risk factors, which also suggested that some AKI after AMI can be avoided. We should shorten the time from admission to reperfusion and avoid the use of larger dosage of intravenous loop diuretics. All of these can prevent the occurrence of AKI in patients with insufficient basal renal reserve and hemodynamic changes. Finally, the two prediction scores created by Queiroz and Abusaada were without validation. we not only randomly selected $70 \%$ patients as derivation cohort but also $30 \%$ patients as validation cohort, and the AUC were 0.79 and 0.81 , respectively; while the Hosmer-Lemeshow $P$-values were 0.63 and 0.60.

The prediction score is easy to be calculated and also has a certain clinical practicality. With eight common clinical variables, the prediction score is relatively simple to calculate. If we use this prediction score in AMI patient, then we can get the corresponding AKI risk score. It is very helpful for clinicians to have a preliminary judgment on the risk of the AMI patients belongs to. High risk and very high risk patients may be required with frequents monitoring, preventive strategies, and even with priority treatment, in order to be with a well renal outcome finally.

Although our prediction score is based on large data, however there must be some limitations with it because that is a retrospective analysis from a single center, so its inherent weakness cannot be avoided. The more accurate incidence of AKI described in our study might be underestimated, which because some patients might already have kidney injury before presentation although we used Scr level on admission to calculate baseline renal function.

\section{Conclusion}

We have developed a validated prediction score to predict AKI in patients with AMI. The application of such a predictive tool may help clinicians to have a preliminary judgment on the AKI risk of the AMI patients. Hence frequents monitoring, preventive strategies, and even with priority treatment should be given to the high risk patients, in order to be with a well renal outcome finally in AMI patients.

\section{Abbreviations}

AKl: acute kidney injury; AKIN: acute kidney injury network; AMI: acute myocardial infarction; AUC: area under the receiver operating characteristic curve; Cl: confidence interval; eGFR: estimated glomerular filtration rate; MDRD: modification of Diet in Renal Diseases; OR: odds ratio; ROC: receiver operating characteristic; SCr: serum creatinine; STEMI: ST-segment elevation myocardial infarction; CIN: contrast-induced nephropathy

\section{Acknowledgments}

We really appreciate Professor Jing Liu for their constructive comments concerning statistical analyses.

\section{Funding}

This research was supported by the following grants: Capital Foundation of Medical Developments (CFMD 2018-2-1051, 2011-2006-07) and Capital Research Foundation of Clinical Characteristics (D101100050010017). The funding bodies had no role in the design of the study; collection, analysis, and interpretation of data; and in writing the manuscript.

\section{Availability of data and materials}

The data used during the current study are available from the corresponding author on reasonable request.

\section{Authors' contributions}

Conception and design of the study by HC and YPC. FBX, TY and HJZ were responsible for collecting the data. Data analysis was performed by FBX and NY. FBX and $\mathrm{HC}$ drafted the manuscript. The final version of the manuscript was read and approved by all authors.

\section{Ethics approval and consent to participate}

The study was approved by the Ethics Committee of Beijing Anzhen Hospital (approval number 2018014X). Due to the retrospective nature of the study, this study was performed with an approved waiver of informed consent.

Consent for publication

Not applicable.

\section{Competing interests}

The authors declare that they have no competing interests.

\section{Publisher's Note}

Springer Nature remains neutral with regard to jurisdictional claims in published maps and institutional affiliations.

Received: 31 May 2018 Accepted: 13 May 2019

Published online: 30 May 2019

References

1. Fox CS, Muntner P, Chen AY, Alexander KP, Roe MT, Wiviott SD. Short-term outcomes of acute myocardial infarction in patients with acute kidney injury: a report from the National Cardiovascular Data Registry. Circulation. 2012;125:497-504

2. Maewni G, Cabiati A, Bertoli SV, Assanelli E, Marana I, De Metrio M, Rubino M, Moltrasio M, Grazi M, Campodonico J, Milazo V, Veglia F, Lauri G, Bartorelli AL. Incidence and relevance of acute kidney injury in patients hospitalized with acute coronary syndromes. Am J Cardiol. 2013;111:816-22.

3. Bruetto RG, Rodrigues FB, Torres US, Otaviano AP, Zanetta DM, Burdmann EA. Renal function at hospital admission and mortality due to acute kidney injury after myocardial infarction. PLoS One. 2012;7:e35496.

4. Amin AP, Salisbury AC, McCullough PA, Gosch K, Spertus JA, Venkitachalam L, Stolker JM, Parikh CR, Masoudi FA. Trends in the incidence of acute kidney injury in patients hospitalized with acute myocardial infarction. Arch Intern Med. 2012;172:246-53.

5. Sun YB, Liu BC, Zou Y, Pan JR, Tao Y, Yang M. Risk factors of acute kidney injury after acute myocardial infarction. Ren Fail. 2016;38:1353-8.

6. Zambetti BR, Thomas F, Hwang I, Brown AC, Chumpia M, Ellis RT, Naik D, Khouzam RN, Ibebuogu UN, Reed GL. A web-based tool to predict acute kidney injury in patients with ST-elevation myocardial infarction: development, internal validation and comparison. PLoS One. 2017;12: e018658. 
7. Kim MJ, Choi HS, Oh SH, Lee HC, Kim CS, Choi JS, Park JW, Bae EH, Ma SK,

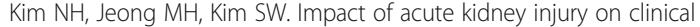
outcomes after ST elevation acute myocardial infarction. Yonsei Med J. 2011;52:603-9.

8. Rodrigues FB, Bruetto RG, Torres US, Otaviano AP, Zanetta DM, Burdmann EA. Incidence and mortality of acute kidney injury after myocardial infarction: a comparison between KDIGO and RIFLE criteria. PLoS One. 2013; 8:e69998.

9. National Institute for Health and Care Excellence (NICE). Acute kidney injury: prevention, detection and management of acute kidney injury up to the point of renal replacement therapy. 2013

10. Liao Y, Dong X, Chen K, Fang Y, Li W, Huang G. Renal function, acute kidney injury and hospital mortality in patients with acute myocardial infarction. J Int Med Res. 2014;42:1168-77.

11. Hsieh MJ, Chen YC, Chen CC, Wang CL, Wu LS, Wang CC. Renal dysfunction on admission, worsening renal function, and severity of acute kidney injury predict 2-year mortality in patients with acute myocardial infarction. Circ J. 2013;77:217-23.

12. Marenzi G, Cosentino N, Bartorelli AL. Acute kidney injury in patients with acute coronary syndromes. Heart. 2015;101:1778-85.

13. Vavalle JP, van Diepen S, Clare RM, Hochman JS, Weaver WD, Mehta RH, Pieper KS, Patel MR, Patel UD, Armstrong PW, Granger CB, Lopes RD. Renal failure in patients with ST-segment elevation acute myocardial infarction treated with primary percutaneous coronary intervention: predictors, clinical and angiographic features, and outcomes. Am Heart J. 2016;173:57-66.

14. Akgul O, Uyarel H, Pusuroglu H, Isiksacan N, Turen S, Erturk M, Surgit O, Celik O, Oner E, Birant A, Akturk IF. High BNP level as risk factor for acute kidney injury and predictor of all-cause mortality in STEMI patients. Herz. 2014;39:507-14.

15. Moriyama N, Ishihara M, Noguchi T, Nakanishi M, Arakawa T, Asaumi $Y$, Kumasaka L, Kanaya T, Miyagi T, Nagai T. Admission hyperglycemia is an independent predictor of acute kidney injury in patients with acute myocardial infarction. Circ J. 2014;78:1475-80.

16. Shacham Y, Gal-Oz A, Leshem-Rubinow E, Arbel Y, Keren G, Roth A, Steinvil A. Admission glucose levels and the risk of acute kidney injury in nondiabetic ST segment elevation myocardial infarction patients undergoing primary percutaneous coronary intervention. Cardiorenal Med. 2015:5:191-8.

17. Shacham Y, Leshem-Rubinow E, Gal-Oz A, Arbel Y, Keren G, Roth A, Steinvil A. Relation of time to coronary reperfusion and the development of acute kidney injury after ST-segment elevation myocardial infarction. Am J Cardiol. 2014;114:1131-5.

18. Tsai TT, Patel UD, Chang TI, Kennedy KF, Masoudi FA, Matheny ME, Kosiborod M, Amin AP, Weintraub WS, Curtis JP. Validated contemporary risk model of acute kidney injury in patients undergoing percutaneous coronary interventions: insights from the National C ardiovascular data registry Cath-PCI registry. J Am Heart Assoc. 2014;3:e001380.

19. Fan PC, Chen TH, Lee CC, Tsai TY, Chen YC, Chang CH. ADVANCIS score predicts acute kidney injury after percutaneous coronary intervention for acute coronary syndrome. Int J Med Sci. 2018;15:528-35.

20. Duan C, Cao Y, Liu Y, Zhou L, Ping K, Tan MT, Tan N, Chen J, Chen P. A new Preprocedure risk score for predicting contrast-induced acute kidney injury. Can J Cariol. 2017:33:714-23.

21. Gao YM, Li D, Cheng H, Chen YP. Derivaton and validation of a risk score for contrast-induced nephropathy after cardiac catheterization in Chinese patients. Clin Exp Nephrol. 2014;18:892-8.

22. Queiroz RE, de Oliveira LS, de Albuquerque CA, Santana Cde A, Brasil PM, Carneiro LL, Libório AB. Acute kidney injury risk in patients with ST-segment elevation myocardial infarction at presentation to the ED. Am J Emerg Med. 2012;30:1921-7.

23. Abusaada K, Yuan C, Sabzwari R, Butt K, Maqsood A. Development of a novel score to predict the risk of acute kidney injury in patient with acute myocardial infarction. J Nephrol. 2017;30:419-25.

24. Thygesen K, Alpert JS, White HD. Joint ESC/ACCF/AHA/WHF task force for the redefinition of myocardial infarction. Universal definition of myocardial infarction. Eur Heart J. 2007;28:2525-38.

25. Mehta RL, Kellum JA, Shah SV, Molitoris BA, Ronco C, Warnock DG, Levin A, Network AKI. Acute kidney injury Network: report of an initiative to improve outcomes in acute kidney injury. Crit Care. 2007;11:R31.

26. Ma YC, Zuo L, Chen JH, Luo Q, Yu XQ, Li Y, Xu JS, Huang SM, Wang LN, Huang W, Wang M, Xu GB, Wang HY. Modified glomerular filtration rate estimating equation for Chinese patients with chronic kidney disease. J Am Soc Nephrol. 2006;17:2937-44.

27. DeLong ER, DeLong DM, Clarke-Pearson DL. Comparing the areas under two or more correlated receiver operating characteristic curves: a nonparametric approach. Biometrics. 1988;44:837-45.

28. Killip T 3rd, Kimball JT. Treatment of myocardial infarction in a coronary care unit. A two year experince with 250 patients. Am J Cardiol. 1967;20:457-64.

29. Marenzi G, Cosentino N, Moltrasio M, Rubino M, Crimi G, Buratti S, Grazi M, Milazzo V, Somaschini A, Camporotondo R, Cornara S, De Metrio M, Bonomi A, Veglia F, De Ferrari GM, Bartorelli AL. Acute kidney injury definition and in-hospital mortality in patients undergoing primary percutaneous coronary intervention for ST-segment elevation myocardial infarction. J Am Heart Assoc. 2016:5:e003522

30. Goussot S, Mousson C, Guenancia C, Stamboul K, Brunel P, Brunet D, Touzery C, Cottin Y, Zeller M. N-terminal fragment of pro B-type natriuretic peptide as a marker of contrast-induced nephropathy after primary percutaneous coronary intervention for ST-segment elevation myocardial infarction. Am J Cardiol. 2015;116:865-71.

31. Lazaros G, Tsiachris D, Tousoulis D, Patialiakas A, Dimitriadis K, Roussos D, Vergopoulos E, Tsioufis C, Vlachopoulos C, Stefanadis C. In-hospital worsening renal function is an independent predictor of one-year mortality in patients with acute myocardial infarction. Int J Cardiol. 2012;155:97-101.

32. Shacham Y, Gal-Oz A, Ben-Shoshan J, Keren G, Arbel Y. Prognostic implications of acute renal impairment among ST elevation myocardial infarction patients with preserved left ventricular function. Cardiorenal Med. 2016;6:143-9.

33. He L, Wei Q, Liu J, Yi M, Liu Y, Liu H, Sun L, Peng Y, Liu F, Venkatachalam MA, Dong Z. AKI on CKD: heightened injury, suppressed repair, and the underlying mechanisms. Kidney Int. 2017;92:1071-83.

34. Krummel T, Bazin D, Faller AL, Hannedouche T. Hypertensive nephrosclerosis. Presse Med. 2012;41:116-24.

35. Dasgupta I, Porter C, Innes A, Burden R. "Benign" hypertensive nephrosclerosis. QJM. 2007;100:113-9.

36. Kuji S, Kosuge M, Kimura K, Nakao K, Ozaki Y, Ako J, Noguchi T, Yasuda S, Suwa S, Fujimoto K, Nakama Y, Morita T, Shimizu W, Saito Y, Hirohata A, Morita $Y$, Inoue T, Nishimura $K$, Miyamoto $Y$, Ishihara M, Investigators JMINUET. Impact of acute kidney injury on in-hospital outcomes of patients with acute myocardial infarction - results from the Japanese registry of acute myocardial infarction diagnosed by universal definition (J-MINUET) substudy. Circ J. 2017;81:733-9.

37. Jolly SS, Shenkman H, Brieger D, Fox KA, Yan AT, Eagle KA, Steg PG, Lim KD, Quill A, Goodman SG, Investigators GRACE. Quantitative troponin and death, cardiogenic shock, cardiac arrest and new heart failure in patients with non-ST-segment elevation acute coronary syndromes (NSTE ACS): insights from the global registry of acute coronary events. Heart. 2011;97: 197-202.

38. Villa G, Samoni S, De Rosa S, Ronco C. The pathophysiological hypothesis of kidney damage during intra-abdominal hypertension. Front Physiol. 2016;7: 55.

39. Smit M, Hofker HS, Leuvenink HG, Krikke C, Jongman RM, Zijlstra JG, van Meurs M. A human model of intra-abdominal hypertension: even slightly elevated pressures lead to increased acute systemic inflammation and signs of acute kidney injury. Crit Care. 2013;17:425.

40. Chen KP, Cavender S, Lee J, Feng M, Mark RG, Celi LA, Mukamal KJ, Danziger J. Peripheral edema, central venous pressure, and risk of AKI in critical illness. Clin J Am Soc Nephrol. 2016;11:602-8.

41. Gambardella I, Gaudino M, Ronco C, Lau C, Ivascu N, Girardi LN. Congestive kidney failure in cardiac surgery: the relationship between central venous pressure and acute kidney injury. Interact Cardiovasc Thorac Surg. 2016;23:800-5.

42. Mazzeffi MA, Stafford P, Wallace K, Bernstein W, Deshpande S, Odonkor P, Grewal A, Strauss E, Stubbs L, Gammie J, Rock P. Intra-abdominal hypertension and postoperative kidney dysfunction in cardiac surgery patients. J Cardiothorac Vasc Anesth. 2016;30:1571-7.

43. Shacham Y, Leshem-Rubinow E, Gal-Oz A, Arbel Y, Keren G, Roth A, Steinvil A. Acute cardio-renal syndrome as a cause for renal deterioration among myocardial infarction patients treated with primary percutaneous intervention. Can J Cardiol. 2015;31:1240-4.

44. Newby LK, Rutsch WR, Califf RM, Simoons ML, Aylward PE, Armstrong PW, Woodlief LH, Lee KL, Topol EJ, Van de Werf F. Time from symptom onset to treatment and outcomes after thrombolytic therapy. GUSTO-1 Investigators. J Am Coll Cardiol. 1996;27:1646-55. 
45. Bradley EH, Nallamothu BK, Herrin J, Ting HH, Stern AF, Nembhard IM, Yuan CT, Green JC, Kline-Rogers E, Wang Y, Curtis JP, Webster TR, Masoudi FA, Fonarow GC, Brush JE Jr, Krumholz HM. National efforts to improve door-toballoon time. results from the door-to-balloon alliance J Am Coll Cardiol. 2009;54:2423-9.

46. Lameire N, Van Biesen W, Vanholder R. Acute renal failure. Lancet. 2005;365: $417-30$.

47. Wang YN, Cheng H, Yue T, Chen YP. Derivation and validation of a prediction score for acute kidney injury in patients hospitalized with acute heart failure in a Chinese cohort. Nephrology (Carlton). 2013;18:489-96.

48. Mahesh B, Yim B, Robson D, Pillai R, Ratnatunga C, Pigott D. Does furosemide prevent renal dysfunction in high-risk cardiac surgical patients? Results of a double blinded prospective randomised trial. Eur J Cardiothorac Surg. 2008;33:370-6.

\section{Ready to submit your research? Choose BMC and benefit from:}

- fast, convenient online submission

- thorough peer review by experienced researchers in your field

- rapid publication on acceptance

- support for research data, including large and complex data types

- gold Open Access which fosters wider collaboration and increased citations

- maximum visibility for your research: over $100 \mathrm{M}$ website views per year

At $\mathrm{BMC}$, research is always in progress.

Learn more biomedcentral.com/submissions 